\title{
NATURE
}

\section{Almost a Good Bargain}

The University Grants Committee has done well, in all the circumstances, to negotiate a reasonably generous agreement on the quinquennium starting in 1968. Only a few months ago, it seemed as if there would be all kinds of deprivation in the period immediately ahead. Not merely did it seem as if the economic pressures on the British Government would make it hard actually to provide the money which the universities will need if they are to continue to grow. There was also a period during which it seemed as if the Government was flirting with the notion that a period of stagnation in the universities would do no serious harm. That at least was the impression created by much of the oversanguine talk about the future development of polytechnics which accompanied the first statements about the potential benefits of the binary system now emerging for British higher education. In the event, it seems as if the universities will be able to grow steadily although not exuberantly in the five years ahead. That is something to be glad about.

In terms of the recurrent grant, there will be an increase of 28 per cent in the five years ahead, and an accompanying increase of roughly 22 per cent in the student population, which suggests that the universities should be able fairly comfortably to keep their heads above water. Indeed, this simple comparison may considerably underestimate the strength of the position of the universities, for there is some evidence of slack in the university system as things are at present. There is, for example, scope for making much better use of the skills and energies of university teachers. The expansion of the past five years has also enabled the universities to recruit people to their staffs more quickly than they are able to deploy them in the teaching force. With skill and good housekeeping, the universities as a whole should be able to keep ticking over comfortably in the next quinquennium.

But this is only half the story. Nobody's interest will be served if the universities grow bigger but stay the same in the quinquennium ahead. And by now it is clear for all to see that these five years will see the introduction of a great many innovations in the pattern of university teaching. One consequence is that the universities will-or should - find themselves spending more heavily on new kinds of lecture rooms, new kinds of ancillary aids to the teaching process and even on new kinds of teaching. This will, and should, be comparatively expensive, which suggests that the comparatively modest grants- $£ 16$ million next year rising to $£ 18$ million in five years-which the UGC is now being given for equipment and furniture may be the first component of the new budget to show obvious signs of strain. And although there is obviously no point in fighting battles before they are engaged, the universities would do well to make early preparations for a thorough study of the ways in which educational innovations may change the character of university teaching and the scale of their demands on the public purse.

The other side of this coin is that the quinquennium ahead should see important steps towards a much more economical use of the capital equipment now locked up in the universities. It is now several years since it became possible to talk safely, in university common rooms, of schemes for adding an extra term to the university year, for example, or for making changes in the ratio of teachers to undergraduates which has had the status of a magic number (one to nine for undergraduates and one to three for postgraduates) ever since the Robbins Committee reported. So far, however, talk has tended to become a substitute for change. There is, however, good reason to believe that moderate reforms along these and other lines could bring important economies and greater freedom for the universities as a whole. It would also help towards the same objectives if the universities were to take more vigorous steps towards regional planning among themselves. Britain is now so thickly sprinkled with universities that the attempt to create from scratch virtually identical educational establishments in cities separated by thirty miles or so is often extravagant and sometimes absurd. But there is also a case for asking that the universities collectively should somehow encourage a greater diversity among themselves. The attempts of the UGC to push towards this worthy objective have not been markedly successful, which is not much of a surprise. The universities themselves could win great benefits by this means, however, and this is something which they ought to work towards in the quinquennium now ahead.

\section{Who Should Keep the Books?}

So the British Government has decided not to build a new British Museum Library, or any other, at Bloomsbury. Instead, it intends to go back to square one and to think quickly about the functions a national library should fulfil and the best means of achieving

them with existing libraries. Although the way the Government announced this decision is deplorable, the decision itself may well prove to be right. That entirely depends on what sort of national library is eventually created, where it is built, and whether or 